Plant Tissue Cult. \& Biotech. 28(1): 69-76, 2018 (June)

$\overline{\text { PTC\&B }}$

\title{
Clonal Propagation and Karyomorphological Study of Solanum torvum Swartz: An Ethnobotanical Species of Tripura, India
}

\section{H. Reshmi Singha*, Sangram Sinha and Rabindra Kumar Sinha}

Cytogenetics and Plant Biotechnology Laboratory, Department of Botany, Tripura

University, Suryamaninagar, Tripura-799022, India

Key words: Solanum toroum, Ethnobotanical Plant, Nodal Culture, Clonal

Propagation, Karyomorphology

\begin{abstract}
An efficient method of clonal propagation through nodal culture of Solanum torvum Swartz. is described. Different concentrations of BAP/Kn alone or in combination with IAA were tested for direct shoot bud induction and proliferation. Lower concentration of $\mathrm{BAP} / \mathrm{Kn}$ alone produced better shoot proliferation and elongation. Maximum number of shoot proliferation was achieved from MS supplemented with $\mathrm{Kn} 0.5 \mathrm{mg} \Lambda$ with an average $4.0 \pm 1.41$ shoots during 28 days of culture. Addition of IAA to the culture media in combination with BAP/Kn significantly reduced the number of shoot formation. Regenerated plants also produced roots during subsequent culture in the same media supplemented with BAP $K n$ alone or in combination with IAA. The easy nature of in vitro rooting of $S$. torvum was recorded without any separate root induction phase. Regenerated plants were successfully transferred to the field condition. Clonal feature was cytologically confirmed through the study of mitotic metaphase chromosomes of regenerated plants which reveals $2 n=24$ somatic chromosomes. Comparative karyomorphological details between the mother and regenerated plants of $S$. torvum revealed close similarity in their chromosomal complements and falls under the category of "1B" Stebbin's symmetric index suggesting true to type nature of the regenerated plant.
\end{abstract}

\section{Introduction}

Tripura state is enriched with many non-traditional ethnobotanical plant species (Mao et al. 2009, Chowdhury et al. 2010). Solanum toroum is an ethnobotanical species under Solanaceae growing wild in Tripura. The species is commonly seen in the road sides, edges of cultivated fields, open fields and wastelands. Fruits

*Author for correspondence: <reshmisingha90@gmail.com>. 
are generally consumed by local tribal community as vegetable and infrequently available in the local markets (Choudhury et al. 200, Deb et al. 2013). In addition S. torvum is reported to be a common ingredient in Thai cuisine (Arthan et al. 2002). Different parts of this plant are used in the treatment of various diseases. Fume of the burning seeds is inhaled for toothache (Bhakuni et al. 1969). Fruits are effective in treatment of cough, cold, liver and spleen enlargement (Priyanaka et al. 2014). It also possesses an antioxidants, antibacterial and antidiabetic activities (Agrawal et al. 2010). The species contain steroidal alkaloid solasonine, torvogenin, torvoside and torvanol (Iida et al. 2005, Smith et al. 2008). In recent times multidimensional utility and significance of the $S$. torvum have been well described and documented (Jaiswal 2012). There has been a tremendous pressure on the natural existence of the species due to increase in various anthroprogenic activities and lack of any domestication or organised cultivation practices in this region. An in vitro propagation technique has always been an effective and alternative measure to conserve and sustainable management of production of desired elite clones of promising species (Bekim et al. 2015, Rameshkumar et al. 2017). Therefore, tissue culture study of promising edible wild Solanum species is important for their efficient regeneration and conservation. Less attention was given to the tissue culture study of $S$. torvum growing wild in this north-eastern region of India. Hence, the present study was conducted to find out the suitable plant growth hormone for efficient in vitro morphogenesis and regeneration of $S$. torvum using nodal explants. This is also aimed at establishing an efficient regeneration protocol for future conservation and sustainable production of elite clones of S. torvum.

\section{Materials and Methods}

Plant species was collected from natural populations of Suryamaninagar, West Tripura with a geographical coordinates N23 46 $13.7^{\prime \prime}$ and E091 ${ }^{\circ} 15^{\prime} 47.3^{\prime \prime}$ from the 30 meter elevation. Plant species was identified in consultation with authentic floristic literature Flora of Tripura (Deb 1983). After proper identification herbarium sheet was prepared and submitted to the Herbarium centre, Department of Botany, Tripura University with a collection number TUH-464.

Healthy shoot tip from identified natural population of $S$. toroum was taken and thoroughly washed under running tap water to remove adherent from the shoot tips. Shoot tips were kept in 1\% polyvenyl pyrolidone (PVP) solution for 3 - $4 \mathrm{hrs}$ to reduce the browning problem. Then the shoot tips were dipped in $0.5 \%$ Bavistin solution for $10 \mathrm{~min}$ and washed with sterile distilled water for three times. This was followed by $0.5 \%$ detergent solution for $5-7 \mathrm{~min}$. Subsequently the explants were washed in sterile distilled water for 3-4 times. Finally the 
explants were treated with $0.1 \% \mathrm{HgCl}_{2}$ solution for $1 \mathrm{~min}$ in front of the laminar airflow and washed 2 - 3 times by sterile distilled water. Final shoot tip explant size measuring $5 \mathrm{~mm}$ was used to establish sterile culture. Shoot tip growth and elongation was achieved in MS media supplemented with BAP (2.0 mg/). Culture derived nodal explants were used as secondary explants for direct shoot proliferation and clonal multiplication in MS containing 3\% sugar supplemented with different concentrations of BAP and $\mathrm{Kn}$ and auxins (IAA). Mediun was adjusted to $\mathrm{pH} 5.7-5.8$ and solidified using $0.9 \%$ agar and sterilized in $121^{\circ} \mathrm{C}$ for $20 \mathrm{~min}$. Culture was maintained by regular sub-culturing of 14 days interval at $25 \pm 2^{\circ} \mathrm{C}$ in $16 \mathrm{hrs}$ light and $8 \mathrm{hrs}$ of dark period. After the complete regeneration rooted plants were transferred to the small pots containing soilrite, soil and sand

in $1: 1: 1$ ratio and kept in the greenhouse. Finally the plants were transferred to the field condition under the sunlight.

Mitotic chromosome study was carried out following standard aceto-orcein squashing technique (Sharma and Sharma 1980) with minor modification. Root tips from the in vitro raised plant as well as from the naturally grown plants were pre-treated with saturated paradichlorobenzene and 8-hydroxyquinoline in $1: 1$ ratio for $5.30 \mathrm{hrs}$ and fixed in $1: 3$ acteic ethanol mixture for overnight and next day treated with $45 \%$ acetic acid and $1 \mathrm{~N} \mathrm{HCl}$. Root tips were stained in $2 \%$ acetoorcein for 2 - $3 \mathrm{hrs}$ at room temperature and squashed using $45 \%$ acetic acid. After squashing chromosome plates were observed under compound light microscope. At least five well spread metaphase plates were drawn using camera lucida under oil immersion objective and photographs were taken using Sony cyber shot camera. The total haploid chromosomal length, total forma percentage $(\mathrm{TF} \%)$ and disparity index (DI) was calculated for both the mother plant as well as regenerated plant for comparison and presented in a tabular form.

\section{Results and Discussion}

Different concentrations of cytokinin BAP/Kn $(0.5-4.0 \mathrm{mg} /)$ were tested for shoot multiplication and elongation with nodal explants. Combination of cytokinin and auxin is often used to induce the new shoot formation (Song 2010). Therefore, the effect of combination of IAA with BAP/Kn was also tested in present study. The presence of cytokinin alone or in combination with auxin resulted in varying degrees of shoot bud induction and shoot proliferation (Fig. $1 \mathrm{~A})$. Among the growth regulator tested, the lower concentration of BAP and Kn $(0.5 \mathrm{mg} /)$ showed better result in formation of new shoots (Table 1). Highest number of shoot proliferation was observed in medium supplemented with $\mathrm{Kn}$ $0.5 \mathrm{mg} \Lambda$ and with an average number of shoots $4.0 \pm 1.41$ during 4 weeks of culture. Moderate to optimum shoot elongation $(5.0 \pm 0.89-6.7 \pm 2.48 \mathrm{~cm})$ was 
recorded in MS containing low cytokinin either BAP or Kn during 28 days of culture. However, relatively better shoot growth was observed in media supplemented with low level of Kn (Fig. 1B). In contrast high concentration of

Table 1. Effect of growth regulators on shoot bud induction and proliferation on nodal explants of $S$. torvum after 4 weeks of culturing.

\begin{tabular}{|c|c|c|c|c|c|}
\hline \multicolumn{3}{|c|}{$\begin{array}{l}\text { Plant growth } \\
\text { regulators } \mathrm{mg} A\end{array}$} & \multirow{2}{*}{$\begin{array}{l}\text { No. of shoots per } \\
\text { explant } \\
\text { Mean } \pm \text { Sd }\end{array}$} & \multirow{2}{*}{$\begin{array}{l}\text { No. of leaf per } \\
\text { plant/shoot } \\
\text { Mean } \pm \text { Sd }\end{array}$} & \multirow{2}{*}{$\begin{array}{l}\text { Average length of } \\
\text { shoot }(\mathrm{cm}) \\
\text { Mean } \pm \text { Sd }\end{array}$} \\
\hline BAP & $\mathrm{Kn}$ & IAA & & & \\
\hline 0.5 & - & & $3.2 \pm 1.16^{\mathrm{ab}}$ & $8.2 \pm 1.6^{\mathrm{bc}}$ & $5.5 \pm 1.41^{\mathrm{ab}}$ \\
\hline 1.0 & - & & $2.2 \pm 1.16^{\mathrm{bcd}}$ & $8.4 \pm 2.87 \mathrm{bc}$ & $5.7 \pm 1.77 \mathrm{ab}$ \\
\hline 2.0 & - & & $2.0 \pm 1.26^{\mathrm{bcd}}$ & $7.6 \pm 5.0^{\mathrm{bc}}$ & $5.0 \pm 0.89 \mathrm{abc}$ \\
\hline 4.0 & - & & $1.2 \pm 0.74^{\mathrm{d}}$ & $5.4 \pm 3.2^{c}$ & $1.6 \pm 0.96^{\mathrm{d}}$ \\
\hline 0.5 & - & 0.5 & $2.2 \pm 1.17 \mathrm{bcd}$ & $6.6 \pm 2.87 c$ & $5.9 \pm 2.80^{\mathrm{ab}}$ \\
\hline 1.0 & - & 0.5 & $1.6 \pm 0.80^{\mathrm{cd}}$ & $4.2 \pm 2.13^{c}$ & $3.8 \pm 2.04^{\mathrm{abcd}}$ \\
\hline \multirow[t]{8}{*}{8.0} & - & 0.5 & $2.2 \pm 0.4^{\mathrm{bcd}}$ & $7.0 \pm 2.76^{c}$ & $1.98 \pm 0.8^{\mathrm{d}}$ \\
\hline & 0.5 & & $4.0 \pm 1.41^{\mathrm{a}}$ & $10.4 \pm 5.85^{\mathrm{bc}}$ & $6.2 \pm 2.48^{\mathrm{ab}}$ \\
\hline & 1.0 & & $2.0 \pm 0.63^{\mathrm{bcd}}$ & $13.6 \pm 0.81^{\mathrm{ab}}$ & $6.4 \pm 2.15^{\mathrm{ab}}$ \\
\hline & 2.0 & & $2.8 \pm 1.16^{\mathrm{abc}}$ & $17.2 \pm 7.0^{a}$ & $6.7 \pm 2.48^{a}$ \\
\hline & 4.0 & & $1.0 \pm 0.63^{\mathrm{d}}$ & $6.6 \pm 4.17 \mathrm{c}$ & $2.5 \pm 1.41^{\mathrm{cd}}$ \\
\hline & 0.5 & 0.5 & $1.4 \pm 0.80^{\mathrm{cd}}$ & $6.4 \pm 2.42^{c}$ & $5.2 \pm 0.98^{\mathrm{abc}}$ \\
\hline & 1.0 & 0.5 & $1.0 \pm 0.00^{\mathrm{d}}$ & $5.6 \pm 0.80^{c}$ & $5.4 \pm 1.74^{\mathrm{ab}}$ \\
\hline & 4 & 0.5 & $1.2 \pm 0.40^{\mathrm{d}}$ & $6.0 \pm 1.26^{c}$ & $3.5 \pm 1.18^{\mathrm{bcd}}$ \\
\hline
\end{tabular}

Data represent treatment means $\pm \mathrm{Sd}$ followed by different letters within the olumn indicate significant differences according to one way ANOVA and DMRT test $(\mathrm{p}<0.05)$.

cytokinin did not support shoot elongation and growth. This observation is in corroboration with previous records on several micropropagation studies (Rai et al. 2012, Zakia et al. 2013, Mehdi et al. 2014). Presence of cytokinin at higher concentration in the medium lead to reduced number of shoot formation. This may be due to self sufficient nature of explant for cytokinin and addition of less cytokinin may act as a trigger to initiate development (Tejavathi and Bauvana 1996). The lower BAP (0.5 $\mathrm{mg} \Lambda)$ concentrations also induced new shoot formation with an average $3.2 \pm 1.16$ numbers of shoots. This study is in contrary to the earlier report on micropopagation of A. rotunda L. (Gatti and Vecchi 2017). Addition of IAA to the culture media in combination with either BAP or $\mathrm{Kn}$ reduces the formation of new shoots. In case of rooting, the regenerated shoots forms visible roots with in the shooting medium containing BAP/Kn (0.5 - 1.0 $\mathrm{mg} \Lambda$ ) in combination with IAA $0.5 \mathrm{mg}$. However MS containing BAP or Kn 
alone also produced visible roots during long term incubation in culture. This observation clearly suggested easy rooting nature of the regenerated clones under prolong period of culture. The rooted plants were properly hardened by transferring to liquid medium and then to the tap water (Fig. 1C). The regenerated clones were transferred to the potted mixture of soilrite, sand and soil in $1: 1: 1$ ratio (Fig. 1 D). Finally, the plants were transferred to the field condition (Fig. 1E) and growing normal.

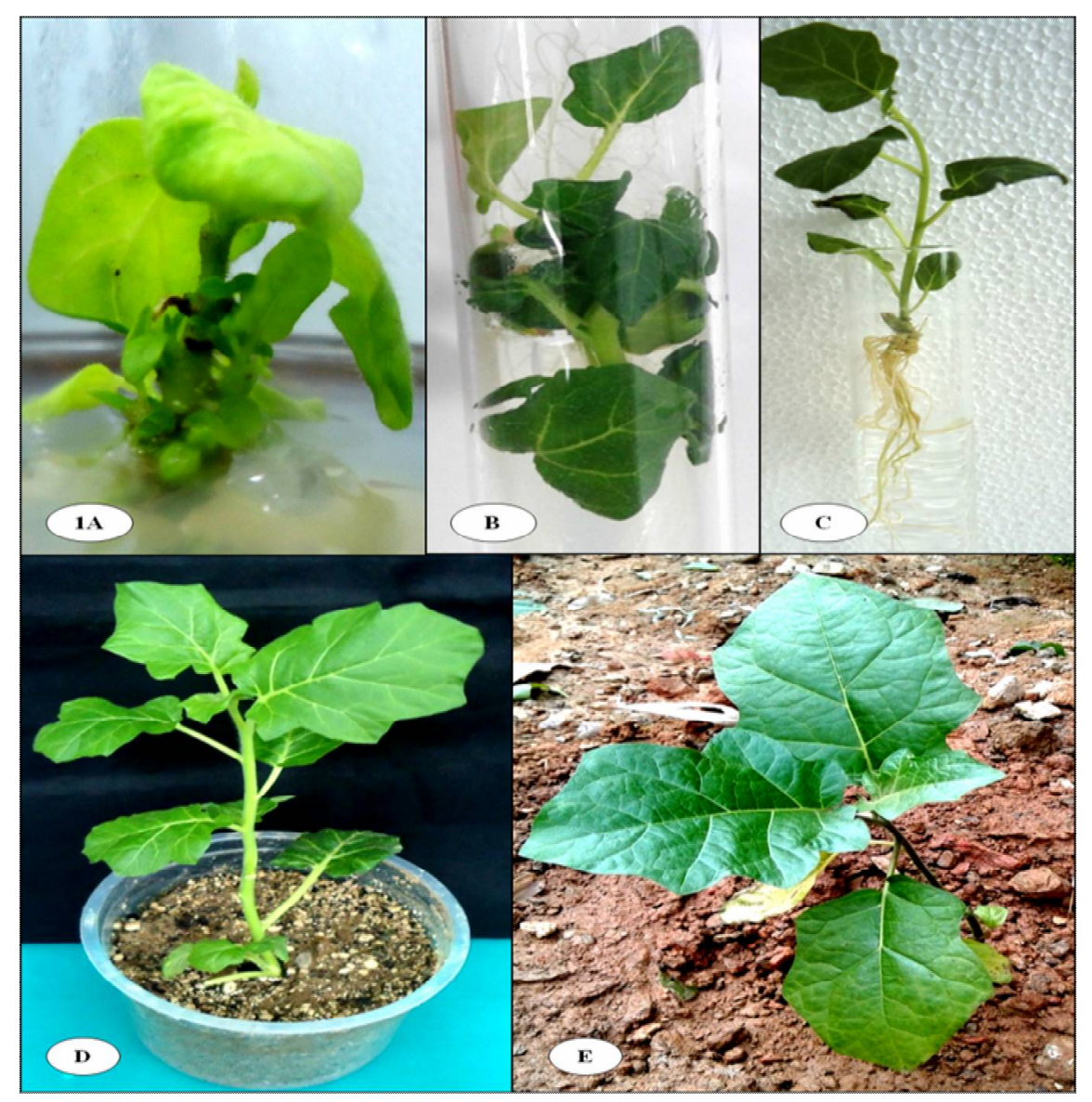

Fig. 1A-E: In vitro clonal propagation of Solanum torvum Swartz. A. multiple shoot formation. B. Shoot growth and elongation. C. Rooted plant. D. Rooted plants growing in a potting mixture. E. Field transfer of the cloned plant.

Mitotic metaphase chromosome study from mother plant as well as regenerated plants revealed $2 \mathrm{n}=24$ somatic chromosomes (Fig. 2A,B) which conformed the earlier report in mother plants of S. torvum (Das 2015). Chromosomes are small in size differing in their position of centromere and 
Table 2. Comparative karyomorphological details of mother plant and regenerated plant of S. torvum.

\begin{tabular}{lcccccc}
\hline $\begin{array}{l}\text { Solanum } \\
\text { torvum }\end{array}$ & $\begin{array}{c}\text { Somatic } \\
\text { chromosome } \\
\text { number (2n) }\end{array}$ & $\begin{array}{c}\text { Total haploid } \\
\text { chromosome } \\
\text { length }\end{array}$ & $\begin{array}{c}\text { Karyotype } \\
\text { formula }\end{array}$ & TF\% & DI & $\begin{array}{c}\text { Stebbin's } \\
\text { degree of } \\
\text { symmetry }\end{array}$ \\
\hline $\begin{array}{l}\text { Mother } \\
\text { plant }\end{array}$ & 24 & 35.44 & $\mathrm{~A}_{2} \mathrm{~B}_{4} \mathrm{C}_{16} \mathrm{D}_{2}$ & 43.48 & 41.37 & $1 \mathrm{~B}$ \\
$\begin{array}{l}\text { Regenerated } \\
\text { plant }\end{array}$ & 24 & 33.53 & $\mathrm{~A}_{2} \mathrm{~B}_{4} \mathrm{C}_{16} \mathrm{D}_{2}$ & 45.69 & 34.53 & $1 \mathrm{~B}$ \\
\hline
\end{tabular}

Mean of five metaphase plate.
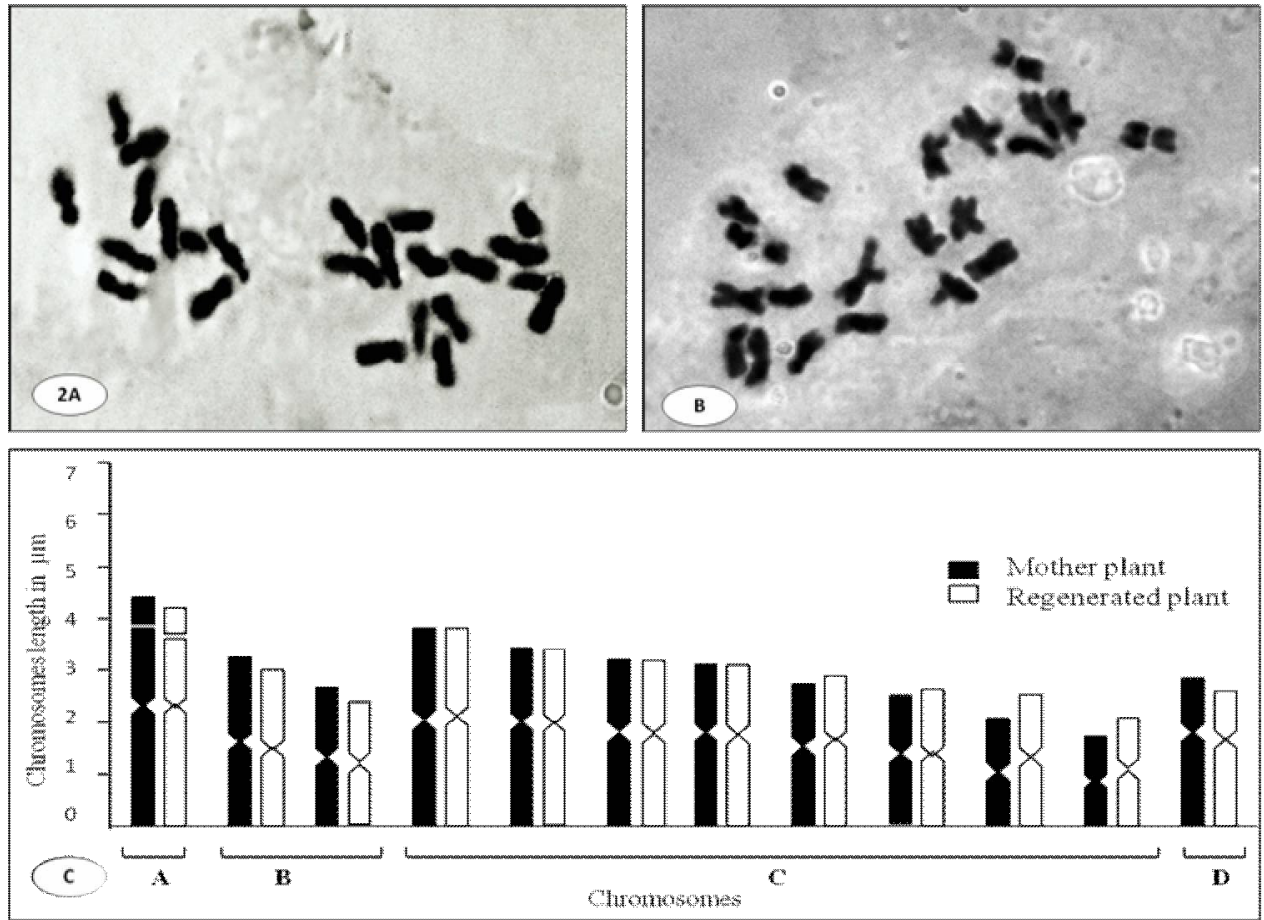

Fig. 2 A-C: Chromosomal details of regenerated and mother plants of Solanum torvum. A. somatic metaphase plate of regenerated plant of showing $2 n=24$. B. Somatic metaphase plate from mother plant showing $2 \mathrm{n}=24$ (x1400). C. Composite ideogram comparing length of the chromosome,position of centromere and secondary constriction between chromosomes of diploid cells in metaphase from mother and regenerated plants .

grouped into four categories (Levan 1964). Chromosomal complements represented one pair of sub-median chromosomes bearing secondary constrictions, two pairs of median, eight pairs of nearly median and one pair of sub-median chromosomes. According to Stebbin's degree of symmetric index (1971) chromosomes are found to fall under the category of "1B" indicating 
slightly inclined to asymmetric karyotype in nature (Table 2). Comparative karyotype analysis of somatic metaphase chromosomes between the mother plant and regenerated plants of $S$. torvum clearly revealed close similarity in their karyomorphological details (Fig. 2C). Thus present study highlights an efficient method of in vitro clonal propagation of Solanum torvum - an useful ethnobotanical species of Tripura, India.

\section{Acknowledgement}

The first author (HRS) is highly thankful to UGC, Govt. of India for providing UGC-BSR fellowship to carry out the present piece of work.

\section{References}

Agrawal AD, Bajpei PS, Patil AA and Bavaskar SR (2010) Solanum torvum Sw. Phytopharmacological review. Scholar Research Library 2(4): 403-407.

Arthan D, Svasti J, Kittakoop P, Pittayakhachonwut D, Tanticharoen $\mathbf{M}$ and Thebtaranonth Y (2002) Antiviral isoflavonoid sulphate and steroidal glycosides from the fruits of Solanum torvum. Phytochemistry 59(40): 459-463.

Bekim G, Kasamedin A, Valbona S and Efigieni K (2015) Micropogation and in vitro conservation of the rare and threatened plants Ramonda serbica and Ramonda nathaliae. Physiol. Mol. Biol. Plants 21(1): 123-136.

Bhakuni DS, Dhar ML, Dhar MM, Dhawan BN and Mehrotra BN (1969) Screening of Indian Plants for Biological Activity: Part II. Indian J. Exp. Biol. 7: 250-262.

Choudhury R, Datta choudhury M, De B and Paul SB (2008) Phytochemical studies and analgesic activity of certain ethnomedicinal plant of Tripura state, India. Asian J. Chem. 20(1): 741-744.

Choudhury R, Datta Choudhury M, De B and Paul SB (2010) Importance of certain tribal edible plants of Tripura. Indian J. Traditional Knowledge 9(2): 300-302.

Das AK and Borah SP (2015) Assessment of genetic diversity among some important wild species of non-tuberous Solanum using RAPD and ISSR markers. International J. Bioscience 6(3): 1029-1042.

Deb DB (1983) The flora of Tripura. Today and Tomorrow printers and publishers.Vol-II.

Deb D, Sarkar A, Deb Barma B, Datta BK and Majumda K (2013) Wild Edible Plants and Their Utilization in Traditional Recipes of Tripura, Northeast India. Advances in Biological Research 7(5): 203-211.

Gatti E and Vecchi M (2017) Micropopagation of Aristolochia rotunda L. Plant Biosystemsan International Journal Dealing with All Aspects of Plant Biology 151(4): 581-583.

Iida Y, Yanai Y, Ono M, Ikeda T and Nohara T (2005) Three unusal 22-beta-O-23hydroxy( 5 alpha)- spirostanol glycosides from the fruits of Solanum torvum. Chem Pharm. Bull. (Tokyo) 53(9): 1122-1125.

Jaiswal BS (2012) Solanum torvum: A review of its traditional uses, phytochemistry and pharmacology. Int. J. Pharm. Bio.Sci. 3(4): 104 -111. 
Levan AK, Fredga K and Sandberg A (1964) Nomenclature for centromeric position Chronosomes. Hereditas 52: 201-220.

Mao AA, Hynniewta TM and Sanjappa M (2009) Plant wealth of Northeast India with reference to ethnobotany. Ind. J. Trad. Knowledge 8(1): 96-103.

Mehdi FA, Maheran AA, Nurashikin K and Ismanizan (2014) Effect of cytokinin types, concentrations and their interactions on in vitro shoot regeneration of Chlorophytum borivilianum Sant. \& Fernandez. Electron. J. Biotechnol. 17(6).

Priyanka A, Yogananth N, Ali MS and Anuradha V (2014) Antibacterial and antifungal activity of Solanum torvum Sw. An ethnomedicinal plant. International Journal of Comprehensive Research in Biological Sciences 1(3): 6-12.

Rai GK, Singh M, Rai NP, Bhardwaj DR and Kumar S (2012) In vitro propagation of spine gourd (Momordica dioca Roxb.) and assessment of genetic fidelity of micropopagated plants using RAPD analysis. Physiol. Mol. Biol. Plants 18(3): 273-280.

Rameshkumar R, Largia MJV, Satish L, Shilpa J and Ramesh M (2017) In vitro mass propagation and conservation of Nilgirianthus ciliates through nodal explants: A globally endangered, high trade medicinal plants of Western Ghats. Plant Biosystems 151(2): 201-211.

Sharma AK and Sharma A (1980) Chromosome technique - Theory and Practice, Third edition. Butterworths Ltd. London.

Smith SW, Giesbrecht E, Thompson M, Nelson LS and Hoffman RS (2008) Solanaceous steroidal glycoalkaloids and poisoning by Solanum torvum, the normally edible susumber berry. Toxicon 52(6): 667-676.

Song JY, Iyyakkannu S, Chul GA and Byoung RJ (2010) Adventitious shoot regeneration from leaf explants of miniature paparika (Capsicum annuum). Hivita red and Hivita yellow. African journal of Biotechnology 9(19): 2768-2773.

Stebbins GL (1971) Chromosomal evolution in higher plant. Edward Arnold. London.

Tejavathi DH and Bauvana B (1996) Micropropagation of Solanum viarum Dunal through cotyledonary node, shoot tip and nodal cultures. Journal of Phytology Research 9: 101-105.

Zakia S, Najma Y Z, Mehwish Y, Nadeem AA, Ashfaq AH and Nasir M (2013) Standardization of micropropgation techniques for Aloe vera: A pharmaceutically important plant. Pak. J. Pharm. Sci. 26(6): 1083-1087. 